\title{
Functional outcome and quality of life 5 and 12.5 years after aneurysmal subarachnoid haemorrhage
}

\author{
Paut Greebe • Gabriël J. E. Rinkel • \\ Jeannette W. Hop · J. M. Anne Visser-Meily • \\ Ale Algra
}

Received: 5 February 2010/Revised: 24 June 2010/Accepted: 5 July 2010/Published online: 22 July 2010

(C) The Author(s) 2010. This article is published with open access at Springerlink.com

\begin{abstract}
Patients who recover from aneurysmal subarachnoid haemorrhage (SAH) often remain disabled or have persisting symptoms with a reduced quality of life (QoL). We assessed functional outcome and QoL 5 and 12.5 years after SAH. In a consecutive series of 64 patients with mean age at SAH of 51 years, initial outcome assessments had been performed at 4 and 18 months after $\mathrm{SAH}$. At the initial and current outcome assessments, functional outcome was measured with the modified Rankin Scale (mRS) and QoL with the SF-36 and a visual analogue scale (VAS). We studied the change in outcome measurements over time. We used the non-parametric Wilcoxon test to compare differences in mRS grades and calculated differences with corresponding $95 \%$ confidence intervals in the domain scores of the SF-36 and the VAS.
\end{abstract}

P. Greebe · G. J. E. Rinkel - A. Algra

Department of Neurology and Neurosurgery, Rudolf Magnus Institute of Neuroscience, Heidelberglaan 100, 3484 CX Utrecht, The Netherlands

J. W. Hop

Department of Child and Adolescent Psychiatry, Rudolf Magnus Institute of Neuroscience, Utrecht, The Netherlands

J. M. A. Visser-Meily

Department of Rehabilitation and Sports Medicine, Rudolf

Magnus Institute of Neuroscience, Utrecht, The Netherlands

\section{A. Algra}

Julius Center for Health Sciences and Primary Care,

University Medical Center, Utrecht, The Netherlands

P. Greebe $(\bowtie)$

Department of Neurology, H02.128, Rudolf Magnus

Institute of Neuroscience, University Medical Center Utrecht,

Heidelberglaan 100, 3484 CX Utrecht, The Netherlands

e-mail: p.greebe@umcutrecht.nl
After 5 years, seven patients had died and five patients had missing data. Compared with the 4-month follow-up, the mRS had improved in 29 of the 52 patients, remained similar in 19 patients. The overall QoL (SF-36 domains and VAS score) was better. At 12.5 years an additional six patients had died. Compared to the 4-month study, 25 of the 46 remaining patients had improved mRS, 12 had remained the same and in nine patients the mRS had worsened. Between the 5 and the 12.5 years follow-up, the improvement in mRS had decreased but patients reported overall a better QoL. Among long-time survivors, QoL may improve more than a decade after SAH.

Keywords Cerebral aneurysm .

Subarachnoid haemorrhage $\cdot$ Quality of life

\section{Introduction}

Subarachnoid haemorrhage (SAH) from a ruptured aneurysm carries a poor prognosis. Within the first month after the haemorrhage, one-third of the patients die [1]. Of those who survive the initial weeks, one-third are disabled in the first month after the haemorrhage [1,2], but recovery continues after this period. In a cohort study 4 and 18 months after the haemorrhage, half the patients had improved on the modified Rankin Scale (mRS) with at least one point $[2,3]$. Of the patients who were independent $(\mathrm{mRS}<4)$ at 18 months after the haemorrhage, many experienced a reduced quality of life (QoL). Because most patients are between 40 and 60 years old at the time of the haemorrhage, functional disability and QoL may further improve. If disability and QoL remain reduced in the long term, this can have considerable impact for patients and for health economics. We assessed the extent of changes in 
functional outcome and QoL after 5 and 12.5 years in a prospectively collected cohort of patients with aneurysmal SAH.

\section{Methods}

We studied a prospectively collected, consecutive series of 98 patients with aneurysmal SAH admitted to the University Medical Centre Utrecht between September 1995 and September 1996. Aneurysmal SAH was diagnosed if CT scanning confirmed the presence of subarachnoid blood and if an aneurysm was found on conventional-, CT- or MR-angiography. Patients with a non-aneurysmal cause of the SAH were excluded. Thirty of the 98 enrolled patients had died during their clinical course, two had been excluded from the previous study because they did not speak Dutch and two patients had declined participation in the study. Thus, our study consisted of 64 patients. Between 4 and 18 months three patients had died [3], but their deaths were not directly related to the SAH.

For the 5- and 12.5-year outcome assessments, we first contacted the general practitioner of the patient to find out if the patient was still living. If not, we asked for the date and cause of death. If the address of the patient was unknown to the general practitioner, we verified it via the municipal archives. Patients who had no telephone were sent a letter and asked to call us. We asked the patient by telephone to answer the same questionnaire as the one we used at the 4- and 18-month follow-ups.

\section{Instruments}

For assessment of disability, we applied the mRS [4], a frequently used functional outcome instrument in stroke. The $\mathrm{mRS}$ is a 6-point handicap scale that focuses on restrictions in lifestyle. The Rankin scale is easy to administer, available in a validated Dutch version and reliable in terms of interobserver agreement [4]. This Dutch version is also validated for telephone assessment [5]. For assessment of QoL we used the medical outcome study short form 36 (SF-36), a validated instrument to assess general QoL and a visual analogue scale (VAS). The SF-36 is brief (5-10 $\mathrm{min})$ and measures eight health-related domains: physical functioning (10 items), role limitations due to physical health problems (4 items), bodily pain ( 2 items), general health perceptions (5 items), vitality (4 items), social functioning ( 2 items), role limitations due to emotional problems (3 items) and general mental health (5 items). The SF-36 scores are calculated by assignment of predefined weights to the different items and range per domain from 0 (maximum reduction in QoL) to 100 (no reduction in QoL). The validity and reliability of the SF-36 have been studied extensively, including the Dutch version [6-9]. The VAS ranged from 0 (poor) to 100 (excellent) just by asking the patient to put a mark on this scale for overall well-being.

\section{Data collection}

All questionnaires were administered in a semi-structured telephone interview by one experienced research nurse (PG). We started the interview with a short introduction and reminder of the 4- and 18-month QoL studies. If the patient was not able to answer the questions because of severe cognitive deficits, we only recorded the Rankin grade of the patient based on information obtained from the partner.

\section{Data analyses}

To compare differences in Rankin grades and QoL scores between 4 months and 5 years, 4 months and 12.5 years, and 5 years and 12.5 years we used the non-parametric Wilcoxon test. We calculated differences in the domain scores of the SF-36 and of the VAS; the corresponding 95\% confidence intervals $(95 \% \mathrm{CI})$ were based on the paired $t$ test.

\section{Results}

Of the 64 patients with a 4-month follow-up, 45 (70\%) were women. The mean age at that time was $51( \pm \mathrm{SD}$ 12.6) years. Fifty-six patients $(88 \%)$ were in good clinical condition on admission, as assessed with the World Federation of Neurological Surgeons (WFNS) [10] scale (WFNS I $n=35$; WFNS II $n=16$; WFNS III $n=5$ ), and eight were in poor clinical condition (WFNS IV $n=4$; WFNS V $n=4$ ). At time of the 18-month follow-up the study population consisted of 61 patients.

For the 5-year outcome assessment, the mean period of follow-up was 5.5 years after the SAH (range 5.3-5.7 years). Four patients ( 3 women, $1 \mathrm{man}$ ) had died between the 18-month and 5-year outcome assessment. In one patient, the general practitioner said that the cause of death was an unverified SAH that had occurred abroad, and in three it was cancer. We could no longer contact another four patients, as no telephone number was available and the patients did not respond to our letter. Another patient was found, contacted by telephone, but was too deaf to be interviewed. The remaining 52 patients could be contacted and all participated in the 5-year outcome assessment.

For the 12.5-year follow-up, the mean follow-up was 13.3 years after SAH (range 12.8-13.5 years). An additional six patients had died between the 5- and 12.5-year 
outcome assessments. Four of the five patients who were not interviewed at the 5-year outcome assessment were again not interviewed but were still living. One patient declined further participation. The remaining 46 patients, 34 women and 12 men, could be contacted by telephone for the 12.5-year outcome assessment.

\section{Functional outcome}

Figure 1a provides an overview of the mRS grade distribution among patients who were living, deceased or with missing data at the four outcome assessments. Figure $1 \mathrm{~b}$ shows the mRS grade distribution among patients who were living and the patients who had died at each outcome assessment and Fig. 1c shows the mRS grade distribution at each outcome assessment for only those patients who were living. The changes in mRS grades between 4 months and 5 years, 4 months and 12.5 years, and 5 and 12.5 years are shown in Tables 1, 2 and 3. In the 4-month and 5-year follow-up, 19 patients remained the same and 29 patients improved. In 18 of these 29 patients the mRS had improved one point, in 10 it had improved two points, and in one patient it had improved three points. In 12 patients the mRS grade remained the same at the 4-month and the 12.5-year follow-ups. In 25 patients the mRS grade improved, 16 by one point, seven by two points, and two patients by three points. Between the 5- and the 12.5-year follow-up the improvement declined with one patient reporting a heart operation, one a myocardial infarction and another patient a colon cancer. In 30 patients the mRS grade remained the same at 5- and 12.5-year follow-up.

\section{Quality of life in patients}

Table 4 shows the differences for the domains of the SF-36 and the VAS score between 4 months and 5 years, 4 months and 12.5 years, and 5 years and 12.5 years. For the SF-36 domains, role limitations because of physical health problems and role limitations because of emotional problems, the scores are clearly higher (improvement) after
Fig. 1 a Proportion of surviving patients with distribution of mRS grades, deceased and missing patients. b Proportion of surviving patients with distribution of mRS grades, deceased patients. c Proportion of surviving patients with distribution of mRS grades

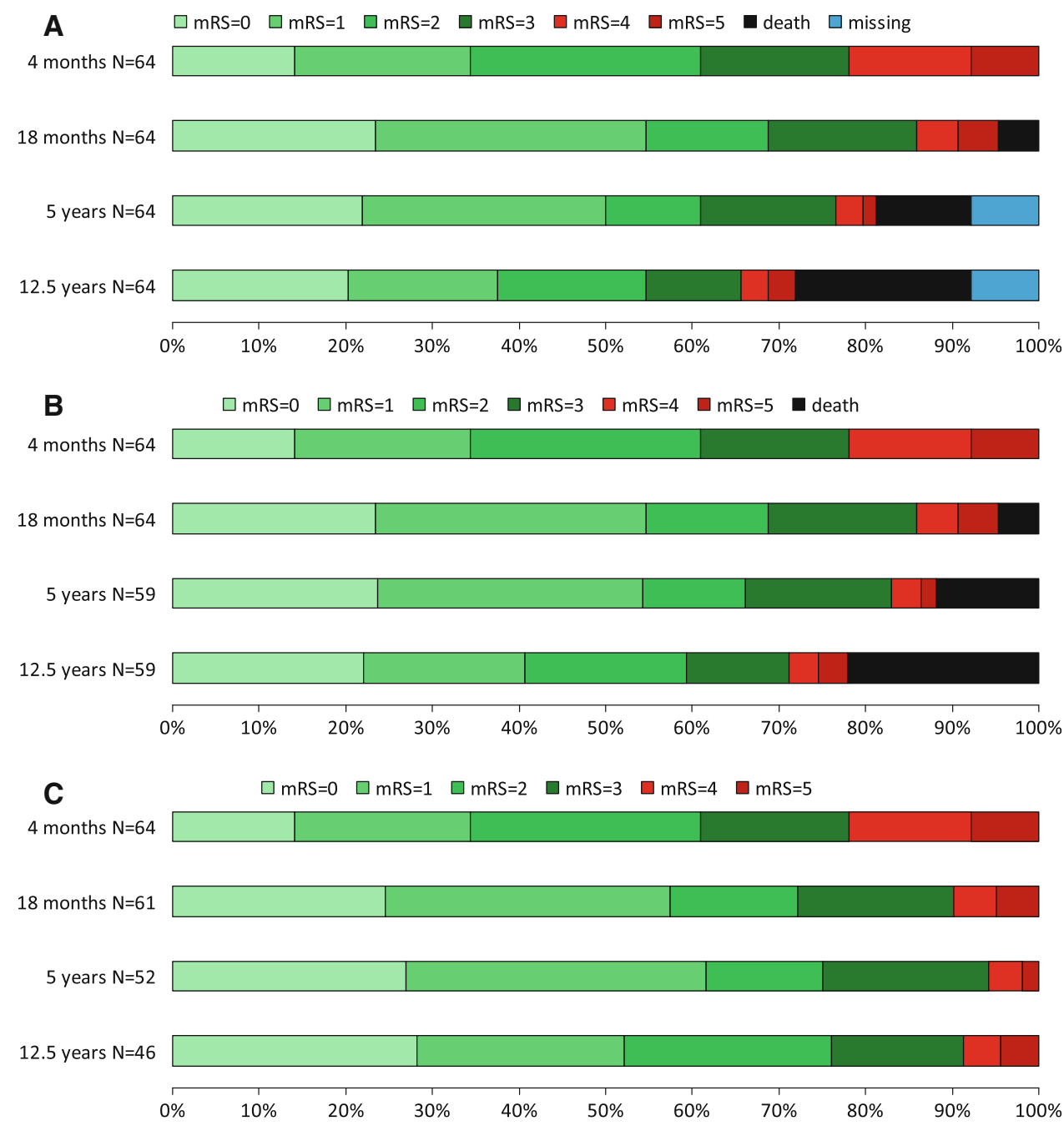


Table 1 Modified Rankin grades at 4-month and 5-year follow-ups

\begin{tabular}{cccccccccc}
\hline & 5 years & \multicolumn{1}{l}{} & & Total \\
\cline { 2 - 9 } & 0 & 1 & 2 & 3 & 4 & 5 & Dead & Missing & \\
\hline 4 months & & & & & & & & & \\
0 & 7 & 2 & - & - & - & - & - & - & 9 \\
1 & 3 & 5 & 1 & 2 & - & - & 1 & 1 & 13 \\
2 & 3 & 6 & 3 & - & - & - & 4 & 1 & 17 \\
3 & 1 & 5 & 2 & 2 & - & - & - & 1 & 11 \\
4 & - & - & 1 & 5 & 1 & - & - & 2 & 9 \\
5 & - & - & - & 1 & 1 & 1 & 2 & - & 5 \\
Total & 14 & 18 & 7 & 10 & 2 & 1 & 7 & 5 & 64 \\
\hline
\end{tabular}

\begin{tabular}{cccccccccr}
\hline & \multicolumn{2}{l}{12.5 years } & & & & & Total \\
\cline { 2 - 8 } & 0 & 1 & 2 & 3 & 4 & 5 & Dead & Missing & \\
\hline 4 months & & & & & & & & & \\
0 & 4 & 2 & - & - & - & - & 2 & 1 & 9 \\
1 & 4 & 2 & 3 & 1 & - & - & 2 & 1 & 13 \\
2 & 4 & 4 & 3 & 2 & - & - & 4 & - & 17 \\
3 & 1 & 2 & 5 & 1 & - & - & 1 & 1 & 11 \\
4 & - & 1 & - & 2 & 1 & 1 & 2 & 2 & 9 \\
5 & - & - & - & 1 & 1 & 1 & 2 & - & 5 \\
Total & 13 & 11 & 11 & 7 & 2 & 2 & 13 & 5 & 64 \\
\hline
\end{tabular}

Table 2 Modified Rankin grades at 4-month and 12.5-year follow-ups functioning. They attributed this reduced physical functioning to other diseases they had, such as osteoporosis, emphysema, cancer, diabetes, heart failure, and impairment of vision and hearing. Despite a reduction in physical functioning between the 5- and 12.5-year outcome assessments, QoL had improved over this period. This suggests that patients continue to adapt and improve while coping with restrictions in functioning. Psychological adaptation has been described also in other chronic diseases [11]. The overall good QoL indicates an improved appreciation of life long after a life-threatening illness. Similar observations have been done in long-term survivors of TIA or minor ischemic stroke who have an overall QoL not much different than the general population [12].

Some limitations of the current study have to be mentioned. To assess disability in terms of functional outcome and QoL, we used the mRS, the SF-36 and a VAS. These outcome measurements had also been used before at the 4and 18-month follow-ups, before the current study was developed. The sickness impact profile (SIP) was also used in the initial outcome assessments, and had similar outcomes at the 4- and 18-month time points but did not discriminate between patients with improved or static 
Table 3 Modified Rankin grades at 5- and 12.5-year follow-ups

\begin{tabular}{|c|c|c|c|c|c|c|c|c|c|}
\hline & \multicolumn{8}{|c|}{12.5 years } & \multirow[t]{2}{*}{ Total } \\
\hline & 0 & 1 & 2 & 3 & 4 & 5 & Dead & Missing & \\
\hline \multicolumn{10}{|l|}{5 years } \\
\hline 0 & 9 & 1 & - & 1 & - & - & 2 & 1 & 14 \\
\hline 1 & 4 & 9 & 4 & 1 & - & - & - & - & 18 \\
\hline 2 & - & 1 & 6 & - & - & - & - & - & 7 \\
\hline 3 & - & - & 1 & 4 & 1 & - & 4 & - & 10 \\
\hline 4 & - & - & - & - & 1 & 1 & - & - & 2 \\
\hline 5 & - & - & - & - & - & 1 & - & - & 1 \\
\hline Dead & - & - & - & - & - & - & 7 & - & 7 \\
\hline Missing & - & - & - & 1 & - & - & - & 4 & 5 \\
\hline Total & 13 & 11 & 11 & 7 & 2 & 2 & 13 & 5 & 64 \\
\hline
\end{tabular}

Wilcoxon tests for comparisons of mRS: 4 months -5 years, $p=0.12 ; 4$ months- 12.5 years, $p=0.58 ; 5-12.5$ years, $p=0.01$

m Rankin scale: 0 , no symptoms at all; 1 , no significant disability despite symptoms; 2 , slight disability; 3 , moderate disability; 4 , moderately severe disability; 5 , severe disability

Table 4 Differences over time in SF-36 and VAS

\begin{tabular}{|c|c|c|c|c|c|c|}
\hline & \multicolumn{4}{|l|}{ Means } & \multicolumn{2}{|l|}{ Differences $(95 \% \mathrm{CI})$} \\
\hline & 4 months & 5 years & 12.5 years & 4 months -5 years ${ }^{\mathrm{a}}$ & 4 months -12.5 years $^{\mathrm{b}}$ & $5-12.5$ years $^{\mathrm{b}}$ \\
\hline \multicolumn{7}{|l|}{ SF-36 } \\
\hline $\mathrm{PF}$ & 68.7 & 74.7 & 77.2 & $6.5(0.6$ to 12.4$)$ & $5.9(-0.3$ to 11.4$)$ & $-1.7(-8.0$ to 4.6$)$ \\
\hline $\mathrm{RP}$ & 24.6 & 62.5 & 91.3 & 34.8 (18.9 to 50.6$)$ & $64.0(50.9$ to 77.1$)$ & $25.0(7.9$ to 42.1$)$ \\
\hline $\mathrm{BP}$ & 75.1 & 85.9 & 92.2 & $7.6(1.2$ to 13.9$)$ & 14.4 (6.3 to 22.6$)$ & $6.0(-1.7$ to 13.6$)$ \\
\hline GH & 70.7 & 73.4 & 71.9 & $0.5(-6.4$ to 7.4$)$ & $-1.2(-8.2$ to 5.8$)$ & $-4.1(-9.4$ to 1.1$)$ \\
\hline VT & 60.1 & 59.8 & 65.3 & $-2.2(-7.9$ to 3.5$)$ & $3.4(-2.5$ to 9.4$)$ & $3.9(-0.5$ to 8.3$)$ \\
\hline SF & 66.3 & 80.7 & 90.4 & $12.0(2.9$ to 21.0$)$ & 22.6 (13.1 to 32.0$)$ & $6.4(-3.0$ to 15.8$)$ \\
\hline $\mathrm{RE}$ & 59.5 & 81.3 & 96.9 & 18.8 (3.3 to 34.4$)$ & $39.0(25.9$ to 52.1$)$ & 13.8 (1.4 to 26.3$)$ \\
\hline $\mathrm{MH}$ & 70.1 & 70.4 & 73.8 & $0.4(-5.0$ to 5.9$)$ & $4.5(-1.3$ to 10.3$)$ & $2.8(-1.2$ to 6.8$)$ \\
\hline PCS & 42.8 & 48.6 & 51.1 & 4.7 (2.1 to 7.4$)$ & 6.7 (3.8 to 9.6$)$ & $1.5(-1.2$ to 4.2$)$ \\
\hline MCS & 47.2 & 49.4 & 52.7 & $1.5(-1.8$ to 4.9$)$ & $5.9(2.7$ to 9.1$)$ & $2.8(0.2$ to 5.8$)$ \\
\hline VAS & 59 & 72 & 76 & $11(5$ to 17$)$ & 16 (9 to 23$)$ & $3(-6$ to 7$)$ \\
\hline
\end{tabular}

$P F$ physical functioning, $R P$ role limitations because of physical health problems, $B P$ bodily pain, $G H$ general health perceptions, $V T$ vitality, $S F$ social functioning, $R E$ role limitations because of emotional problems, $M H$ general mental health, $P C S$ physical summary scale, $M C S$ mental summary scale

${ }^{\mathrm{a}} 46$ pairs; ${ }^{\mathrm{b}} 41$ pairs

Rankin grades [3]. The SIP contains 136 items and is very time-consuming. For both of these reasons we decided not to continue using the SIP for the 5-year and the 12.5-year follow-ups. A disease specific QoL list was not used in 1995. Therefore, we cannot distinguish between disability remaining from the SAH and disability as a result of other, age-related diseases. Another limitation is that the initial cohort of 64 patients is relatively small and all interviews were administered by telephone. However, we demonstrated that telephone assessment of the mRS with a structured interview has as good results as face-to-face assessment [5]. Strong points are that, at the 12.5-year time point, there was no loss to follow-up and all interviews were performed by the same research nurse. As far as we know, this is the first attempt to assess changes in functional outcome and QoL for longer than a decade in patients with SAH. Therefore, we could not compare our results with those from other studies. We conclude that it is 


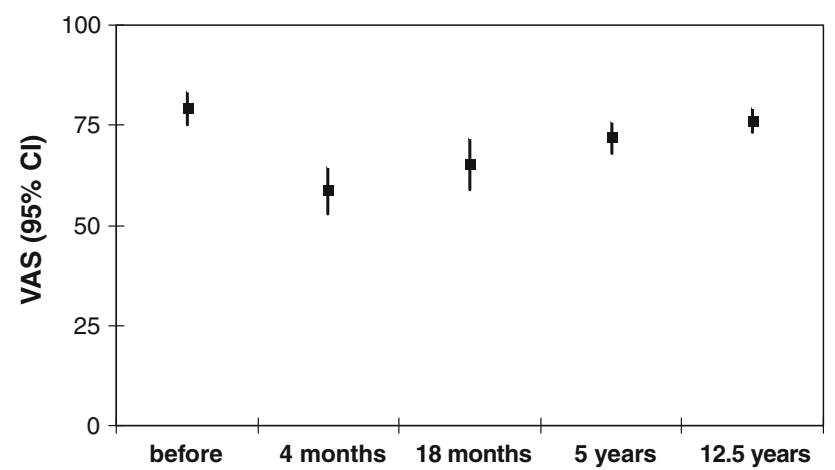

Fig. 2 VAS score according to time

important for patient care to inform patients and their partners that QoL may improve more than a decade after SAH. In further studies the relationship between functional outcome and QoL should be assessed by long-term followup studies, as well as determinants of good outcome long after the SAH.

Acknowledgments We thank Mrs. Dorien Slabbers who located missing patients necessary for this study.

Open Access This article is distributed under the terms of the Creative Commons Attribution Noncommercial License which permits any noncommercial use, distribution, and reproduction in any medium, provided the original author(s) and source are credited.

\section{References}

1. Nieuwkamp DJ, Setz LE, Algra A, Linn FH, de Rooij NK, Rinkel GJ (2009) Changes in case fatality of aneurysmal subarachnoid haemorrhage over time, according to age, sex, and region: a meta-analysis. Lancet Neurol 8(7):635-642
2. Hop JW, Rinkel GJ, Algra A, van Gijn J (1998) Quality of life in patients and partners after aneurysmal subarachnoid hemorrhage. Stroke 29(4):798-804

3. Hop JW, Rinkel GJ, Algra A, van Gijn J (2001) Changes in functional outcome and quality of life in patients and caregivers after aneurysmal subarachnoid hemorrhage. J Neurosurg 95(6):957-963

4. van Swieten JC, Koudstaal PJ, Visser MC, Schouten HJ, van Gijn J (1988) Interobserver agreement for the assessment of handicap in stroke patients. Stroke 19(5):604-607

5. Janssen PM, Visser NA, Dorhout Mees SM, Klijn CJ, Algra A, Rinkel GJ (2009) Comparison of telephone and face-to-face assessment of the modified rankin scale. Cerebrovasc Dis 29(2):137-139

6. Anderson C, Laubscher S, Burns R (1996) Validation of the short form 36 (SF-36) health survey questionnaire among stroke patients. Stroke 27(10):1812-1816

7. McHorney CA, Ware JE Jr, Raczek AE (1993) The MOS 36-item short-form health survey (SF-36): II. Psychometric and clinical tests of validity in measuring physical and mental health constructs. Med Care 31(3):247-263

8. McHorney CA, Ware JE Jr, Lu JF, Sherbourne CD (1994) The MOS 36-item short-form health survey (SF-36): III. Tests of data quality, scaling assumptions, and reliability across diverse patient groups. Med Care 32(1):40-66

9. van der Zee K, Sanderman R, Heyink J (1993) De psychometrische kwaliteiten van de MOS-36 short form health survey (SF36) in een Nederlandse populatie. Tijdschr Soc Geneesk 71:183-191

10. Teasdale GM, Drake CG, Hunt W, Kassell N, Sano K, Pertuiset B, De Villiers JC (1988) A universal subarachnoid hemorrhage scale: report of a committee of the World Federation of Neurosurgical Societies. J Neurol Neurosurg Psychiatry 51(11):1457

11. Kempen GI, Ormel J, Brilman EI, Relyveld J (1997) Adaptive responses among Dutch elderly: the impact of eight chronic medical conditions on health-related quality of life. Am J Public Health 87(1):38-44

12. van Wijk I, Gorter JW, Lindeman E, Kappelle LJ, van Gijn J, Koudstaal PJ, Algra A (2007) Mental status and health-related quality of life in an elderly population 15 years after limited cerebral ischaemia. J Neurol 254(8):1018-1025 